\title{
New insights into the role of androgen and oestrogen receptors in molecular apocrine breast tumours
}

\author{
Richard D lggo*
}

\begin{abstract}
Two recent studies on a rare androgen-dependent form of breast cancer have shed light on the biology of luminal tumours and reinforced the view that interfering with androgen signalling may have a place in the therapy of some forms of breast cancer.
\end{abstract}

Pragmatic clinicians divide breast tumours into three types: those requiring hormonal therapy, those requiring anti-human epidermal growth factor receptor 2 (HER2) therapy and those requiring chemotherapy. Happily, these types correspond to the main groups immortalised by Chuck Perou in the 'intrinsic' classification of breast cancer (luminal, HER2-enriched and basal-like) [1], but it is worth noting that the clustering of gene expression profiles reflects primarily cell type and is only very indirectly related to drug responses. The major biological distinction is between cells with a precursor phenotype (basal-like, also called luminal progenitor) and cells with a differentiated phenotype that equips them to build ducts or secrete milk [2]. The latter are luminal in the sense that they resemble the luminal (inner) cell layer of mammary epithelia. In this sense, the HER2-enriched phenotype is clearly luminal. To avoid confusion I sometimes use the term 'broad luminal' to describe the shared features of anatomically luminal cells. Surprisingly, the unique feature that distinguishes the HER2enriched group from other luminal tumours is not the presence of an ERBB2 amplicon but the absence of oestrogen receptor (ER) expression. At first glance, this loss of ER expression looks like a minor detail in the expression profile but it has profound consequences. Without ER the cells maintain their broad luminal profile

*Correspondence: iggo@bergonie.org

INSERM U916, Bergonie Cancer Institute, University of Bordeaux, 229 cours de I'Argonne, 33076 Bordeaux, France but stray into a shadowy world known to pathologists as apocrine metaplasia. Fibrocystic disease is a common manifestation of apocrine metaplasia in benign mammary tissue. The critical point is that androgen replaces oestrogen as the driving force behind differentiation. Tumours with this phenotype have been given various names, including HER2-enriched, ER-/androgen receptor (AR)+, and triple negative/AR+. I proposed the term 'molecular apocrine' because: 1 , it is not an unpronounceable acronym; 2, many HER2+ tumours have an 'intrinsic' luminal profile rather than a HER2-enriched profile; 3, many tumours with a HER2-enriched profile lack ERBB2 amplicons; 4, it is not biologically meaningful to cast relatively well differentiated tumours as a subdivision of triple negative tumours (a term widely understood to mean progenitor or basal-like); and 5, apocrine glands are androgen-driven glands with a secretory mechanism akin to that of mammary glands, so the term captures the distinctive biology that defines the group [3]. When pathologists say the mammary gland is a sweat gland, they mean an apocrine gland not an eccrine gland. From an evolutionary perspective, the mammary gland is derived from an apocrine gland in the skin of an erstwhile frog (a synapsid) [4]. Somewhere along the way oestrogen supplanted androgen and the mammary gland was born. All luminal cells express AR but it is normally held in check by ER, whose role is to police the frontier between civilised mammary society and apocrine metaplasia. Putting together the biology, the histology, the expression profile, and the genetic data on ERBB2 amplification and germline PTEN (phosphatase and tensin homolog) mutation $[1,5]$, it seems clear that pathological activation of the HER2 signalling pathway in the absence of protective ER signalling sets the stage for mammary cells to revert to their ancestral apocrine fate.

Two recent chromatin immunoprecipitation sequencing (ChIP-seq) papers have shed important new light on the mechanism of molecular apocrine tumour formation $[6,7]$. To many scientists the precision with which ChIPseq can map transcription factor binding on a genomewide scale is nothing short of miraculous. Indeed, 
ChIP-seq is the perfect tool to identify potential changes in AR and ER binding that might accompany apocrine metaplasia. The new papers both used breast cancer cell lines to model molecular apocrine tumours [8]. If they have a weakness, it is perhaps that the available cell lines may not fully capture the spirit of apocrine metaplasia. Setting aside this caveat, the results show an impressive role for androgens in the biology of these tumours. Both studies built on work by the same groups showing that FOXA1 (Forkhead box A1) renders nearby DNA more accessible to ER and AR. In the new work they used ChIP-seq to map AR and FOXA1 binding in MDAMB-453 molecular apocrine cells. They compared it to the pattern of ER and FOXA1 binding in MCF7 breast cancer cells, and to the pattern of AR and FOXA1 binding in $\mathrm{LNCaP}$ prostate cancer cells. Steroid receptors are inventive in their choice of partners, particularly in prostate cells, but the striking result reported by the Carroll lab was the unprecedented extent to which AR and FOXA1 work together to bring AR to oestrogen response elements in MDA-MB-453 cells [7]. This explains why molecular apocrine tumours cluster with luminal tumours in gene expression studies: AR substitutes for ER at the enhancers of ER target genes to sustain the broad luminal profile. At the same time, AR binds to the enhancers of a smattering of its own target genes to give the expression profile its apocrine flavour. The Brown lab went a step further by linking activation of HER2 signalling to AR, but perhaps not as one might have expected. Rather than HER2 signalling to AR, as has been reported by others [9], they found that AR signals to HER2. It does so by inducing the expression of HER3 (ERBB3), a dimerisation partner for HER2. This sets up a positive feedback loop between AR and HER2, which is exactly what we were hoping to see: in metaplasia the cell must flip from a positive feedback loop defining the normal state to a new loop defining the metaplastic state. The route from AR to HER3 includes an interesting detour through WNT signalling: AR activates WNT7B expression, which sends $\beta$-catenin scuttling into the nucleus to help AR transactivate the ERBB3 promoter [6].

This work leaves us with a stronger conviction that androgens are a worthy therapeutic target in molecular apocrine tumours. There is already one trial under way with an anti-androgen drug (bicalutamide) in relapsed molecular apocrine tumours (NCT00468715). My own preference would be to test abiraterone in these tumours. Abiraterone blocks the synthesis of androgens and oestrogens, and has shown promise in prostate cancer [10]. Since it deprives tumours of both androgens and estrogens, classic luminal and molecular apocrine tumours should respond equally well to it. Clinicians could confidently plan and execute such a study without waiting endlessly for labs to come up with the perfect molecular apocrine biomarker. In fact, they could get the diagnosis wrong and the treatment would still work. What more could you ask?

\section{Abbreviations}

AR, androgen receptor; ChIP-seq, chromatin immunoprecipitation sequencing; ER, oestrogen receptor; HER, human epidermal growth factor receptor.

\section{Competing interests}

The author declares that he has no competing interests.

\section{Acknowledgements}

I thank Gaetan MacGrogan and Hervé Bonnefoi for helpful discussions. Work in my lab is funded by the French Cancer League, ANR and INCa.

Published: 8 December 2011

\section{References}

1. Perou CM, Sørlie T, Eisen MB, van de Rijn M, Jeffrey SS, Rees CA, Pollack JR, Ross DT, Johnsen H, Akslen LA, Fluge O, Pergamenschikov A, Williams C, Zhu SX, Lønning PE, Børresen-Dale AL, Brown PO, Botstein D: Molecular portraits of human breast tumours. Nature 2000, 406:747-752.

2. Lim E, Vaillant F, Wu D, Forrest NC, Pal B, Hart AH, Asselin-Labat ML, Gyorki DE, Ward T, Partanen A, Feleppa F, Huschtscha LI, Thorne HJ; kConFab, Fox SB, Yan M, French JD, Brown MA, Smyth GK, Visvader JE, Lindeman GJ: Aberrant luminal progenitors as the candidate target population for basal tumor development in BRCA1 mutation carriers. Nat Med 2009, 15:907-913.

3. Farmer $P$, Bonnefoi $H$, Becette $V$, Tubiana-Hulin M, Fumoleau P, Larsimont D, Macgrogan G, Bergh J, Cameron D, Goldstein D, Duss S, Nicoulaz AL, Brisken C, Fiche M, Delorenzi M, Iggo R: Identification of molecular apocrine breast tumours by microarray analysis. Oncogene 2005, 24:4660-4671.

4. Oftedal OT: The mammary gland and its origin during synapsid evolution. J Mammary Gland Biol Neoplasia 2002, 7:225-252.

5. Banneau G, Guedj M, MacGrogan G, de Mascarel I, Velasco V, Schiappa R, Bonadona V, David A, Dugast C, Gilbert-Dussardier B, Ingster O, Vabres P, Caux F, de Reynies A, Iggo R, Sevenet N, Bonnet F, Longy M: Molecular apocrine differentiation is a common feature of breast cancer in patients with germline PTEN mutations. Breast Cancer Res 2010, 12:R63.

6. Ni M, Chen Y, Lim E, Wimberly H, Bailey ST, Imai Y, Rimm DL, Shirley Liu X, Brown M: Targeting androgen receptor in estrogen receptor-negative breast cancer. Cancer Cell 2011, 20:119-131.

7. Robinson JL, Macarthur S, Ross-Innes CS, Tilley WD, Neal DE, Mills IG, Carroll JS: Androgen receptor driven transcription in molecular apocrine breast cancer is mediated by FoxA1. EMBO J 2011 , 30:3019-3027.

8. Doane AS, Danso M, Lal P, Donaton M, Zhang L, Hudis C, Gerald WL: An estrogen receptor-negative breast cancer subset characterized by a hormonally regulated transcriptional program and response to androgen. Oncogene 2006, 25:3994-4008.

9. Mellinghoff IK, Vivanco I, Kwon A, Tran C, Wongvipat J, Sawyers CL: HER2/neu kinase-dependent modulation of androgen receptor function through effects on DNA binding and stability. Cancer Cell 2004, 6:517-527.

10. de Bono JS, Logothetis CJ, Molina A, Fizazi K, North S, Chu L, Chi KN, Jones RJ, Goodman OB Jr, Saad F, Staffurth JN, Mainwaring P, Harland S, Flaig TW, Hutson TE, Cheng T, Patterson H, Hainsworth JD, Ryan CJ, Sternberg CN, Ellard SL, Fléchon A, Saleh M, Scholz M, Efstathiou E, Zivi A, Bianchini D, Loriot Y, Chieffo N, Kheoh T, et al:: Abiraterone and increased survival in metastatic prostate cancer. NEng J Med 2011, 364:1995-2005.

doi: $10.1186 /$ bcr3036

Cite this article as: Iggo RD: New insights into the role of androgen and oestrogen receptors in molecular apocrine breast tumours. Breast Cancer Research 2011, 13:318. 